\title{
MARXISMO Y SOCIOLOGÍA HOY
}

\section{MARXISM AND SOCIOLOGY TODAY}

\section{Roberto Ayala Saavedra*}

RESUMEN

\begin{abstract}
Este artículo formula algunas proposiciones básicas para estudiar aspectos relevantes de la relación entre marxismo y Sociología. El objetivo ha sido avanzar sobre la forma de abordar la actualización del problema.
\end{abstract}

PALABRAS CLAVE: MARXISMO * SOCIOLOGÍA * HISTORICIDAD * CULTURA * VIDA COTIDIANA

\section{ABSTRACT}

The article formulates some basic propositions to study relevant aspects on the relation between marxism and sociology. The purpose has been to move forward on how to approach the updating of the problem.

KEYWORDS: MARXISM * SOCIOLOGY * HISTORICITY * CULTURE * DAILY LIFE

\section{INTRODUCCIÓN}

Hoy se puede hablar de una historia del debate de las relaciones entre el marxismo (una corriente de pensamiento) y la Sociología (un campo de estudios). Un debate que continúa, que no se puede cerrar, justamente por el carácter de los términos de la relación, que hacen que esta sea inevitablemente abierta, tensionada. Este trabajo abordará el tema no recurriendo a una reconstrucción histórica estricta, sino desde la formulación de algunos de sus aspectos, como contribución a la actualización teórico-metodológica del problema, incorporando algunos de los principales momentos de la reflexión, de los aportes recíprocos y de las cruciales polémicas.

Henri Lefebvre aportó una fórmula muy citada que efectivamente puede ayudar a plantear el problema en un terreno fértil: "Marx no es un sociólogo, pero en Marx hay una Sociología". Se la puede mejorar sustituyendo Marx por 'marxismo'. El marxismo contemporáneo, como marco teórico-metodológico, es más que la sin duda decisiva, cimentadora y en buena medida vigente, contribución de los fundadores, Karl Marx y Friedrich Engels. Este es un asunto curiosamente muy poco asumido $y$

Escuela de Sociología y Maestría en Sociología de la Universidad de Costa Rica (UCR). raas4758a@yahoo.com.ar 
elaborado, lo que en parte se entiende por la diversidad de los cursos de desarrollo, no siempre inmediatamente articulables $y$ no pocas veces directamente conflictivos, de las múltiples elaboraciones posteriores. La actualización del marxismo - tarea permanente- pasa en parte por el examen y recuperación crítica de lo más sólido de su amplia diversidad de desarrollos.

Otra fórmula útil en el punto de arranque de este trabajo puede ser la siguiente: 'el marxismo es más que Sociología y la Sociología es más que marxismo'. Es decir, el marxismo supone una perspectiva transdisciplinaria, en la cual la dimensión caratulada como 'Sociología' se articula a los aspectos económicos, históricos, filosóficos, epistemológicos, de teoría política, psicológicos, antropológicos, éticos, estéticos, etc. Cualquier investigación especializada, teórica o empírica, tiende a articular la construcción de su objeto específico, no importa cuán particular sea, con este marco general; dialéctica de la investigación (teoría/experiencia) que permite sucesivamente avanzar en la exploración precisa del objeto, incorporado en un campo de sentido histórica $y$ conceptualmente amplio y de vuelta, avanzar en la construcción $y$ precisión del marco teórico como un todo, desarrollando su poder explicativo y su potencial heurístico, así como su solidez epistémica. Por otro lado, la Sociología como disciplina incorpora, no sin grandes tensiones (metateóricamente irresueltas), una diversidad de corrientes de pensamiento y contribuciones, más allá del aporte marxista.

Desde estas dos fórmulas, entonces, el problema puede ser colocado en términos de las siguientes interrogantes: ¿cuál ha sido el aporte del marxismo a la Sociología como campo disciplinario? y ¿cómo ha incidido el desarrollo de la Sociología en el marxismo contemporáneo?

Una evidente dificultad preliminar consiste en precisar qué se entiende por 'Sociología' en este trabajo. Un indicador nada desdeñable del estado de desarrollo de la disciplina $y$ en particular, de las dificultades para alcanzar un marco epistémico compartido en el campo, es la ausencia de acuerdo en la definición del objeto de estudio: de Durkheim a Weber, de
Schutz a Luhmann, Goffman o Bauman. Por su parte, Giddens intenta dar cuenta de este problema al proponer una formulación abarcadora pero poco precisa: "La Sociología es el estudio de la vida social humana, de los grupos y sociedades". En seguida incluye en el objeto "nuestro comportamiento como seres humanos, los encuentros efímeros en la calle, los procesos sociales mundiales' (1992, p. 41).

Desde el marxismo por su vez se han ensayado diversas aproximaciones. En relación con el propósito general de este texto, se trabajará con el criterio aportado por diversos autores, la Sociología como Ciencia de la Sociedad ( $y$ del desarrollo social, de los procesos sociales); no del fragmento, del 'hecho', de los 'fenómenos', de la 'acción con sentido', del 'mundo de la vida', del 'self', o de totalidades 'orgánicas', sino de todo ello como tensión dialéctica de lo micro y lo macro, de lo subjetivo $y$ lo objetivo, de las distintas dimensiones $y$ escalas de lo real social, del todo y la parte, de la multiplicidad estructurada y jerarquizada, en movimiento a partir de sus desequilibrios $y$ contradicciones internas $y$ su metabolismo (circuitos de retroacción) con el entorno físico.

Por 'sociedad' hay que entender 'lo real social', en el marco de 'lo real' en general, es decir, el mundo-universo del que se ha llegado a ser parte, como momento diferenciado. En otros términos, 'la sociedad' es la sociedad humana o la humanidad socializada, el conjunto de las relaciones que los seres humanos traban entre sí y que dan lugar a lo que se llama 'vida social'; por eso no se puede hablar de 'individuo', a secas, como gustan los empiristas-liberales, epistemológicamente atomistas, sino de 'individuo social', como dice Marx, no es solo un 'zoon politikon', no solo un animal social, sino un animal que únicamente en sociedad puede transformarse en un individuo-sujeto, desarrollar una identidad personal.

La noción marxista de sociedad puede exponerse mostrando la forma en que tematiza los dos aspectos epistémicos fundamentales, dialécticamente articulados, del problema, la tensionada relación individuo/socialidad y la historicidad de lo humano-social. En El dieciocho brumario de Luis Bonaparte (2003), 
Marx escribe: "Los hombres hacen su propia historia, pero no la hacen a su libre arbitrio, bajo circunstancias elegidas por ellos mismos, sino bajo aquellas circunstancias con que se encuentran directamente, que existen y les han sido legadas por el pasado". Es apenas una de las múltiples maneras de colocar el criterio de base de una 'concepción materialista de la historia y la sociedad', es decir, una concepción inmanentista, que funda el estudio de lo histórico-social en 'las condiciones de existencia y las relaciones recíprocas entre los seres humanos', las condiciones de producción y reproducción de la vida real, material, base y condición de posibilidad general de la evolución social, así como, los conflictos y dinámica sociales que de ahí se derivan.

Sin duda, en relación con la omnipresente tensión entre subjetividad y objetividad ${ }^{1}$, entre libertad y condicionamiento (reino de la necesidad), Engels y Marx han alternado énfasis variados en sus distintos escritos, en orden a dar cuenta de objetivos de investigación-reflexión, y también polémicos, distintos. Pero de conjunto, está más allá de toda objeción el criterio general que atraviesa toda su obra compartida: el 'lado activo' de lo real lo pone la actividad humana, la actividad 'crítico-práctica', la praxis. La 'base económica', en sentido amplio, resultado por su vez de la praxis social, pone el marco de posibilidades históricas, pero estas se resuelven en los movimientos sociales, en las confrontaciones políticas y de ideas. Las estructuras no hacen la historia, la hacen los individuos y los grupos, a partir de sus necesidades e intereses, armados con sus ideas-representaciones sobre el mundo que habitan.

Lo real no debe concebirse solo bajo la forma del 'objeto', de un mundo que aparece como meramente exterior y por tanto extraño $y$ opresivo, sino - desde cierto punto de vista fundamental - 'de un modo subjetivo', como un mundo que es modificado por, $y$ ya en parte

1 Más allá de la conflictividad social estructural $y$ de su posible superación, la estructura pulsional del individuo supone una insuperable fuente de tensiones con la regulación social de la convivencia. Es la dialéctica de impulsos placenteros $y$ de autoconservación. es, $y$ crecientemente, resultado de la actividad humana, es decir, como un mundo que puede ser objetivamente conocido, por aproximaciones sucesivas, alcanzado por el pensamiento, primero, $y$ después transformado, conscientemente $y$ de acuerdo a objetivos racionalmente establecidos. Somos parte del mundo y el mundo puede ser, en la acción social, primero conocido, luego reproducido y transformado, de acuerdo a nuestras necesidades $y$ aspiraciones $^{2}$. En eso consiste la praxis, la piedra angular de toda la 'concepción materialista de la historia' y el fundamento de todo aquello llamado cultura, es decir, de toda construcción, tangible o intangible ('creencias, artefactos e instituciones'), mediadora de la interacción/ comunicación para la intervención asociada sobre la naturaleza, el mundo dado, dirigida a satisfacer necesidades $y$ aspiraciones diversas (biológicas, psíquicas y sociales).

La sociedad, el todo social, en cada momento, no es solo anterior o posterior, no está por encima ni por debajo de los individuos, es el resultado siempre de la interacción de esos individuos y grupos sociales, en condiciones heredadas por el proceso social anterior, que los seres humanos reproducirán o transformarán a partir de sus aspiraciones, intereses y luchas. Respecto de cada individuo, tomado abstractamente, en forma aislada, el todo social es un a priori, una exterioridad independiente, opresiva en su aparente inabarcabilidad $y$ desde tal ángulo, se elaboran diversas teorizaciones en el campo de la disciplina. La consecuencia inesquivable es un organicismo funcionalista, que en una $u$ otra medida acaba reduciendo al sujeto a la sujeción (y que reincide en el positivismo al reducir toda la estructura social a relaciones superficiales o inmediatamente dadas). Es justamente por eso que la 'sociedad' de la teoría solo puede ser concebida, si se pretende una aproximación conceptual y empíricamente satisfactoria, como proceso, como totalidad relacional compleja en movimiento, es decir como devenir de la autoproducción humana.

\footnotetext{
2 Lo real existe independientemente, el conocimiento es una construcción y la praxis modifica el mundo.
} 
Siguiendo la formulación de Engels, muchas veces expresada, hay que tratar la teoría de la sociedad como una ciencia histórica o en otros términos, 'el problema de la historia es la historia del problema'.

La historicidad de lo real social es entonces un asunto de principal importancia. No puede ser concebida como una mera sucesión de eventos, cuya concatenación sería una arbitraria construcción subjetiva del individuo o una simple exterioridad fenoménica, sino como la determinación teórico-metodológica de una dimensión decisiva del objeto como tal (la 'cosa' es proceso), del mundo construido por los seres humanos. Desde un punto de vista marxista, la historicidad escapa de todo relativismo historicista irracionalista, amalgama de singularidades absolutas, entendiéndola como expresando la temporalidad derivada del desarrollo de la actividad social humana, de la praxis reproductora $y$ transformadora, actividad que se realiza en una cierta cambiante relación con el mundo natural y desde unas precondiciones sociales y culturales, obra a su vez de generaciones anteriores $^{3}$. Es tal enfoque el que permite que la historia humana sea racionalmente captable, permitiendo reconstruir las lógicas (las 'leyes', que son regularidades estructurales) subyacentes del desarrollo de lo social-humano, en cada momento, circunstancia o época ${ }^{4}$.

3 Marx rechazaba la tendencia del historicismo de Ranke a reducir la historia a 'un fácil tráfico de anécdotas, que atribuye los grandes acontecimientos a causas mezquinas e insignificantes'. Por su parte, Engels critica en Duhring la 'incomprensión del proceso histórico', $y$ de solo ver en la misma 'un registro repulsivo de ignorancia, barbarie, violencia', lo que le llevaba a ignorar 'la evolución oculta que tenía lugar tras esas ruidosas situaciones del escenario'. El fenomenismo como enfermedad crónica.

"El sentido de la historia es una precondición para una ciencia de la historia. No es una facultad innata, sino cultivada y generada históricamente. La distinción del paso del tiempo entre un pasado bien definido, el presente y el futuro, tiene sus raíces en la evolución de la organización del trabajo. La conciencia humana de que la vida, la temporalidad, es sucesión de acontecimientos cambiantes ha adquirido amplitud $y$ profundidad con el desarrollo y diversificación de la producción social. El
A la historia no puede imponérsele un sentido a priori, pero es inteligible. En otros términos, la historia está efectivamente abierta, pero no puede ser cualquier cosa. El presente es un resultado provisional de una combinación particular de diversos posibles del pasado y condensa, como presente, una situación dada, un instante del curso, del devenir $y$ un conjunto de posibles futuros que darán lugar a una nueva situación, como resultado fundamentalmente no anticipable, dado su carácter de resultado de la lucha, del carácter agonal del proceso social, de las relaciones de confrontación y cooperación de los distintos grupos, fuerzas, intereses e individuos, que pugnan por imponer sus aspiraciones y sus definiciones de la realidad.

El futuro no puede ser preestablecido porque se hace en el presente, en las acciones $y$ las luchas de una pluralidad de fuerzas e intereses, porque justamente por ello, ese futuro no será idéntico al proyecto de ninguna de las fuerzas concurrentes, será el resultado no pretedeterminado de la compleja interacción de los diversos intereses (Engels, 1973). Pero no puede ser cualquier cosa porque está condicionado por las determinaciones del presente, previamente construidas, $y$ el abanico de posibilidades que este porta (en la medida en que la acción humana modifica y en ese sentido 'crea', el mundo, lo subjetivo se torna objetivo - la acción social produce el mundo-, que desde ahí, se hace condición para el ulterior desarrollo de la subjetividad; las condiciones objetivas de la acción social son, en parte y crecientemente, resultado de ese actuar $)^{5}$. Este presente comenzó a nacer en aquel pasado y porta en su seno un futuro, no como un desarrollo lineal, sino de acuerdo a una lógica de los posibles, que se resuelve en las luchas y la confrontación de intereses y

calendario aparece por primera vez no entre los recolectores de alimento, sino en las comunidades agrícolas"(Novack,1977, p.15).

5 En la dialéctica de estructura y acción, la primera antecede siempre como marco a la segunda, histórica y biográficamente. La acción normalmente reproduce la estructura, $y$ puede también modificarla y transformarla. 
proyectos, en el contexto de una sociedad, la capitalista, caracterizada por la explotación del trabajo humano $y$ diversas formas funcionales de opresión.

En uno de sus textos, dice Gadamer: "La aparición de una toma de conciencia histórica es verdaderamente la revolución más importante de las que hemos experimentado tras la llegada de la época moderna" (2003, p. 41). El aporte del idealismo alemán y en particular, de Hegel, a comienzos del siglo XIX, resulta decisivo en esta elevación a representación intelectual, a conciencia filosófica, de uno de los rasgos principales del nuevo tiempo abierto por el triunfo definitivo de la burguesía como clase dominante y la subsecuente retotalización social que a partir de ahí se sigue y se despliega a todo lo largo del siglo, triunfo que puede ser sintetizado en la entronización de la (auto) percepción del sujeto burgués y su hacer como núcleo del 'espíritu del capitalismo', ahora completamente asumido en su caracterizadora secularidad. El sentido de la historicidad, la conquista por el sujeto burgués de la conciencia de su capacidad para crear un mundo, operando sobre el mundo dado, preexistente, transformando el mundo del que hace parte $y$ en ese proceso hacerse a sí mismo, viene a ser uno de los aspectos centrales, definitorios, del emergente espíritu del tiempo, además de -en lo que aquí interesa- precondición fundamental del surgimiento de las ciencias sociales.

Precisamente por esto último, por sus condiciones sociales de emergencia, las ciencias sociales surgen marcadas por una desconcertante limitación, que rápidamente va tornándose en consciente autolimitación, en tanto que elemento de un régimen social que más allá de los grandes avances que inaugura y alienta - la racionalización, la destradicionalización, el deshechizo del mundo y el salto en la individuación- no hace sino inaugurar una nueva forma histórica de la desigualdad social estructural, aunque en un nuevo nivel de la evolución social, un orden social fundado en la propiedad privada de los medios de generación de riqueza $y$ en un mecanismo, de eficacia sin precedente, de explotación del trabajo humano, que además se apoya en la incorporación refuncionalizada de formas de opresión preexistentes; las cuales, con su cada vez más evidente anacronismo, en las nuevas condiciones, no pueden más que contribuir a resaltar el carácter paradójico y contradictorio del nuevo orden social.

Desde El Manifiesto (1973), Engels y Marx dejan claro que en su criterio lo que caracteriza esencialmente al flamante orden social no es una perversidad absoluta, sino su carácter desconcertantemente contradictorio. En términos más generales, 'crea las condiciones para la emancipación humana y en el mismo movimiento, inevitablemente, las cancela', por la propia lógica de su funcionamiento. Tal carácter contradictorio se expresa con singular desgarro en el ámbito de las nacientes ciencias sociales y se agudiza con su desarrollo: la autolimitación institucionalizada del conocer, en particular, de lo real social. De ahí la superficialidad fenomenista, orientada a la descripción y elaboración formal de relaciones observables (que confunde estructura social con conexiones y secuencias visibles), o de aspectos muy parciales, cuando no de la fragmentación distorsionadora premeditada, de lo cual se sigue una reincidencia en el empirismo-positivismo, incapaz de captar al fenómeno como momento del proceso, su campo de sentido.

A inicios del siglo XIX, la burguesía ha protagonizado, a lo largo de quinientos años, una gesta sin parangón. Ha logrado finalmente desplazar el viejo orden social levantado sobre las venerables ruinas de Roma, apuntalado por la institucionalidad teocráticateocéntrica y sostenido por el poder de la aristocracia, en tanto clase dominante. Un mundo basado en el principio de dependencia ha sido finalmente dislocado por otro autoproclamadamente defensor del principio de autonomía. Sin duda, es una gran conquista, un pasaje histórico-universal, que no solo supone un cambio y una transformación de envergadura inusual, en sí misma, sino que directamente ha abierto, en un desarrollo no lineal, la posibilidad histórica real de toda una nueva época en la evolución humana, una liberada de la explotación del trabajo, de la jerarquización clasista y por tanto, del fundamento - directo $o$ indirecto- de las opresiones y la dominación 
política, de la escisión y las condiciones alienantes de la vida social.

Pero el nuevo orden nace atravesado por múltiples y agudas contradicciones, entre ellas, aquella que contrapone, en el plano de las ideologías dadoras de sentido y legitimadoras, por un lado, una estridente defensa formal de la libertad individual, de la cual hace seña identificadora, mientras postula como piedra angular de la arquitectónica social un dispositivo económico ciego, el mercado, concebido en forma naturalizada, deshistorizada $y$ en último término, trascendente; sobre cuyo funcionamiento autónomo, por ello mismo, los seres humanos no deben intervenir, so pena de temibles calamidades, derivadas de la arrogante 'imprudencia racionalista' ejercida contra el orden natural concedido por la gracia divina. El orden burgués dice fundarse en la defensa de la libertad individual y el derecho a la propiedad privada, pero como ya apuntaba Marx, expropia al 98\% de los individuos, cuya única propiedad es su capacidad de trabajo y limita severamente, cuando no frustra del todo, la capacidad de realización personal de los trabajadores $y$ de la mayor parte de la gente. La libertad liberal es 'libertad' solo para unos pocos (y por tanto, para nadie).

En tales condiciones sociales, el surgimiento del conocimiento científico-racional de lo real social, nace marcado por una fractura: una sociedad comparativamente abierta requiere un cierto autoconocimiento a fin de poder desplegar alguna capacidad de autogobierno $y$ de control sobre las fuerzas sociales en las que se asienta (más allá de los mecanismos de autorregulación ciegos, propios del dispositivo del mercado y expresión de los intereses dominantes ${ }^{6}$. Al mismo tiempo, por la

$6 \quad$ Más específicamente, una economía de propietarios privados, que producen sin un plan para un mercado que individualmente no controlan, y que se apoya necesariamente en el trabajo asalariado libre, una economía basada en la competencia, necesita $y$ tiende a generar un marco político igualmente abierto, pluralista y competitivo, a fin de dirimir los inevitables conflictos económicosociales que produce y en los que se apoya. Esto da lugar a otra de las paradojas/contradicciones del orden burgués: una sociedad estructuralmente 'naturaleza' del régimen social, ese autoconocimiento no debe por definición trasponer ciertos límites, los cuales deben ser anatematizados (para los sectores dominantes, reconocer tal 'naturaleza' resultaría 'subjetivamente intolerable y objetivamente disfuncional').

La consolidación del nuevo orden burgués (secularizado y racionalizado, todo un punto de inflexión en la evolución socio-cultural) es la condición de posibilidad del surgimiento $y$ desarrollo de las ciencias sociales, uno de los productos más sofisticados del nuevo clima cultural desplegado por la modernidad burguesa y por esta misma razón, su condición y estatus es paradójica. Desde el ámbito de su autonomía relativa y por su peculiar carácter, las relaciones con el orden social que las ha hecho posibles estarán irremediablemente marcadas por una tensión permanente, que por momentos se torna críticamente aguda, aproximándose a un punto de ruptura, en la versión más próxima a las corrientes del pensamiento y la acción críticas, pero que en su curso principal de desarrollo se desliza hacia una situación de institucionalización desarmadora, donde los enfoques conservadores $y / 0$ reformadores (en el nuevo sentido del liberalismo post $y$ antirevolucionario, tras la gran Revolución Francesa y Emund Burke), imponen su predominio relativo, con los efectos teóricos y metateóricos mediatos correspondientes (dos de las más claras expresiones de ello son el abandono por la economía convencional del problema del carácter y origen del valor (Smith, Ricardo), preocupación central del surgimiento de la disciplina, en los autores clásicos, así como el correlativo olvido/ disimulo de la estructura y el conflicto de clase por buena parte de la Sociología académica, en particular la norteamericana; podría igualmente

de clase que para funcionar y reproducirse necesita inducir, en su exterioridad fenoménica, la atomización de la vida social y la ilusión de la libertad/igualdad formales. Esto permite entender que el liberalismo sea la visión de mundo (ideología) que mejor la expresa y que configura su autorepresentación. Dada la complejidad creciente del orden social, las disciplinas específicas tienden, en su corriente principal, a cubrir la necesidad de información y conocimiento valedero para las agencias de control. 
apuntarse la evolución de los estudios sobre el Estado, desde Locke, o de lo psico-social desde el conductismo, etc.).

En estas condiciones surge el marxismo y es a partir de ellas y del modo particular como interactúa y se curva sobre estas, que se puede entender su especificidad como marco teórico-metodológico, y en particular, sus relaciones con la Sociología como disciplina, con sus variaciones y oscilaciones.

Discutir la especificidad del marxismo, en comparación con otras corrientes de pensamiento social, supone abordar un aspecto fundamental: el marxismo no surge en o vinculado a la academia, aparece no solo en el marco de un movimiento social preexistente, el movimiento socialista/comunista, sino que surge expresamente con el propósito de dotar al movimiento político-social de un sólido fundamento teórico y de método. En cierto sentido, el marxismo es un fruto combinado del proceso político-social de la primera parte del siglo XIX, así como, del respectivo y correlacionado clima intelectual.

El fin del siglo XVIII es un momento histórico como pocos. El triunfo definitivo del orden social burgués (más allá de escaramuzas de diversa importancia que se extenderán hasta mediados del próximo siglo) proyecta su reestructurante influencia sobre la totalidad y cada uno de los distintos niveles del mundo social, con diverso grado de mediación, a partir principalmente de un profundo trastorno y modificación de la estructura social y su funcionamiento, en el que una nueva clase dominante, la burguesía con sus diversos componentes desplaza a la antigua aristocracia, de lo cual se sigue una espectacular transformación del espíritu del tiempo. Desde la Primera Revolución Industrial hasta la gran Revolución Francesa, pasando por un no menos profundo cambio en el clima cultural-intelectual de la época (expresado básicamente en dos transiciones que marcaron pasajes decisivos, la definitiva destrascendentalización de la ciencia moderna, de lo cual Laplace o Lamarck son destacados protagonistas, y el desplazamiento del centro del pensamiento racional de la gran filosofía especulativa por el conocimiento científico positivo ${ }^{7}$ ), el resultado general es todo un salto, un cambio radical, objetiva $y$ subjetivamente en las condiciones $y$ dinámica del proceso histórico.

Dos hechos del clima cultural-científico son destacables en relación con las precondiciones intelectuales de la génesis del marxismo, el definitivo surgimiento de la Biología como ciencia moderna, tras los trabajos de Linneo, Buffon, Spallanzani, Cuvier, Lamarck, entre varios otros, $y$ de la historiografía como saber racional y empíricamente controlado de la evolución social humana. Efectos y causas del curso histórico, el impacto intelectual y social de tales desarrollos será decisivo. El siglo XIX se abre, entonces, con un cambio radical en la concepción general del conocimiento, de un enfoque impregnado del naturalismo mecanicista, en particular derivado de la mecánica newtoniana, a otro u otros que se desarrollarán bajo el impacto del esquema organicista-evolucionista innovado por los biólogos y/o de la perspectiva del devenir incorporada en el abordaje de la historia. Se trata de un cambio radical en el fundamento epistémico del conocer sustantivo, un giro metateórico de modelo explicativo, que se sigue de un avance del saber en el campo del conocimiento positivo. La organicidad y devenir llevan a relacionalidad y proceso, a continuidad y negatividad, a la relación del todo y las partes, $y$ al problema del surgimiento de lo nuevo, al concepto de sistema y a la dialéctica. Finalmente, la concepción general del saber se pone en condiciones de superar definitivamente las persistentes premisas del pensar clásico, que concebían la ciencia como un conocimiento universal, necesario e inmutable.

En un sentido amplio de lo histórico, entendido como génesis-devenir, es decir, como autodesarrollo y autodiferenciación de lo real, más allá del mero acontecer o suceder, una visión en que todo lo que existe puede ser puesto en relación con las condiciones y causas

$7 \quad$ A lo largo del siglo XIX desarrollará una clara deriva tecnologizante, por su vez, expresión del hecho fundamental de que el desarrollo científico estará, bajo el capitalismo cada vez más, integrado al proceso productivo impetuosamente adelantado por la dinámica competitiva del sistema. 
múltiples y no armónicas de su surgimiento, el mundo alcanza independencia ontológica, contra toda trascendencia: existe, evoluciona, por sí mismo, se explica a partir de sí mismo. Así se inmanentiza el concepto de lo real, tanto en el ámbito de la naturaleza, evidenciado en el evolucionismo a partir de Lamarck, el primero en elaborar una interpretación filogenética de los cambios a través del tiempo de los seres vivos, como en el mundo humano, concebido como producción de sí, como producir(se) del ser humano en su praxis social, con muy diversos grados de conciencia.

Las ciencias sociales son hijas de la revolución burguesa, causal y funcionalmente están en relación con las características estructurales $y$ las necesidades de la reproducción (macro y micro) del nuevo orden social, que es su condición de posibilidad. El marxismo comparte este origen, pero es su vertiente crítica. Vertiente que se hace posible justamente por el carácter contradictorio, paradójico, del resultado de la gran transformación social estimulada por el espíritu burgués. Es en relación con este tema que se ha podido hablar de las 'promesas incumplidas de la modernidad'; el nuevo orden social orna su espectacular triunfo definitivo enarbolando las grandes aspiraciones de la emancipación y la realización humana, las cuales impregnan el clima intelectual de fines del siglo XVIII. Durante la primera mitad del siglo XIX parece encaminarse a ritmo acelerado a la creación de las premisas materiales correspondientes. Pero bien pronto comienza a hacerse claro que tales expectativas no se verán realizadas, no dentro de los límites del orden burgués.

La gran contradicción del capitalismo consiste en que revolucionando la capacidad del hombre para generar riqueza y transformar el mundo, amplía espectacularmente las posibilidades de realización humana, pero en la medida en que se funda en la explotación del trabajo, con todas las necesarias concomitancias opresivas, no puede sino volver a obstruir $y$ anular esas oportunidades para no ser desbordado, arrollado, por el proceso al que da lugar. En ese sentido, puede verse al capitalismo como una forma social de transición, espectacular y desgarrada (que no puede sino medirse en siglos), en la que van surgiendo y madurando las condiciones objetivas y subjetivas que preparan o tornan posible, factible (de ninguna manera seguro), el pasaje histórico hacia un nuevo estadio de la evolución social, uno marcado por fundamentalmente dos logros, del todo inéditos: un control básico de los seres humanos sobre el mundo natural y social que habitan (basado principalmente en el conocimiento científico y tecnológico, así como en una transformación radical de la estructura y la relacionalidad social), $y$ un hacer consciente $y$ racional de su propia historia.

Pero este carácter contradictorio del orden burgués, núcleo de su peculiaridad histórica, permite entender el no menos singular hecho de que el pensamiento crítico, en sus diversas expresiones, también sea un producto de la modernidad. Un orden social que no puede no proclamar que se funda en y se orienta a la libertad y la realización, pero que no puede sino frustrar tales aspiraciones, porta en sí mismo su negación superadora. Aunque también puede dar lugar a reacciones involutivas.

Desde este punto de vista, el marxismo como análisis crítico del capitalismo y teoría crítica de la totalidad social, puede ser presentado como uno de los productos más brillantes de la modernidad burguesa y probablemente el más desconcertante. El punto o momento en que la modernidad burguesa, como máxima expresión de su carácter contradictorio, da lugar a un efecto no deseado, el surgimiento de una reflexión teórica (que hace propios todos los avances técnicos de la investigación empírica en ciencias sociales) orientada a elaborar conscientemente las tendencias inherentes al sistema, como medio para informar racionalmente la intervención práctica sobre aquellas que apuntan más allá de sus fronteras. Un futuro que existe como posible real en el presente. Es en esta intervención práctica, en sentido muy amplio, político-intelectual, en la que se desarrolla, se corrige y se actualiza como sistema conceptual.

Entonces, el marxismo surge del conflicto social y para dar una respuesta e incidir de vuelta sobre el movimiento, desde su especificidad como corriente de pensamiento. De ahí la dialéctica de teoría/praxis. Para Hegel, se 
trata de alcanzar el mundo con el pensamiento, lo cual lo coloca más allá de la trampa del escepticismo humeano, que inspiró y limitó a Kant. Para Marx y Engels, de que este conocer, aproximado, relativo e histórico (rompiendo así con el panlogicismo hegeliano), pero objetivo y real, sea además la base racional para su transformación. En esto consiste la proclamada 'superación/realización de la filosofía', del filosofar especulativo, que había alcanzado su cúspide con el idealismo clásico alemán, y que, como parte de la expresión de su grandeza, justamente había contribuido a gestar su propia superación.

En un siglo que pone el escenario para las condiciones apremiantes de una transición de envergadura en la cultura europea, un desplazamiento inédito del centro del dominio intelectual, de la gran especulación racional por la ciencia positiva (en el terreno de la exploración teóricamente orientada y empíricamente controlada del mundo), el marxismo viene a ser una expresión diferenciada del proceso general en el terreno del pensamiento crítico. Lejos de cualquier antiintelectualismo, el marxismo viene a subrayar el valor de la teoría, del trabajo con 'el concepto', pero reivindicando una forma de hacer filosofía que, como reconoce Hegel, en la Fenomenología, no solo no puede ignorar el desarrollo de las ciencias positivas, sino que solo puede hacerse en la más estrecha relación de complementación recíproca. Se trata de transformar el mundo, un mundo no estático, por ello hay necesidad de continuar interpretándolo.

La categoría 'pensamiento crítico' conlleva aspectos que buscan inmunizarlo ante la tendencia dominante de la 'ciencia positiva', bajo las condiciones ideológico-culturales burguesas, a hacerse 'positivista' o más bien, a desarrollar una autoimagen 'positivista', no pocas veces, $y$ sobre todo en sus más logradas y pregnantes expresiones, reñida con su real carácter, bastante más rico y plástico (la teoría científica de los últimos casi 200 años reposa y se desarrolla, en grado diverso, sobre premisas ingenuamente dialécticas, de la geología del Lyell y Wegener a la evolución de Lamarck y Darwin, de la relatividad y la cuántica a la teoría de sistemas, la teoría del caos o el freudismo) (Woods y Grant, 2002 y Moreno, 1981).

Para el marxismo la base de la criticidad es la captación histórico-dialéctica de lo real y de lo real social (contra todo lo aislado y estático, lo lineal e inmediato-aparente, lo eterno y absoluto). Desde Heráclito sabemos que 'todo fluye', lo único que permanece es el cambio. Piaget precisa que no hay génesis sin estructura y la estructura es un sistema de transformaciones, lo cual significa, como dice a su vez Prigogine, que lo real es complejo y deviene. Esta es la base de todo verdadero realismo crítico, lo cual puede ser sintéticamente expresado afirmando que 'el mundo es real, existe independientemente del pensar, pero es inteligible y modificable, apropiable'. Esta es la clave para escapar de todo determinismo mecanicista, también de todo indeterminismo irracionalista: una teoría de la acción transformadora (que es una acción con sentido, finalista), de la crítica práctica. La acción social cambia los términos de la interacción, a partir de sus resultados y así se cambia a sí misma.

El pensar crítico, entonces, busca romper con todo extravío idealista ${ }^{8}$, sustituyéndolo por una ontología materialista: el mundo existe independientemente de toda conciencia y somos parte diferenciada de ese mundo ('somos polvo de estrellas', pero en el más elevado nivel de organización); lo cual lleva a la tesis del realismo epistemológico: el objeto de conocimiento es independiente del sujeto de conocimiento, pero las teorías científicas pueden proporcionar conocimiento valedero sobre la estructura y movimiento de lo real ('el pensamiento puede alcanzar el mundo', en último término, porque la inteligencia es parte $y$ ha surgido evolutivamente de ese

$8 \quad$ Es decir, pensar la dimensión de lo cultural al margen de su relación con la estructura y dinámica de lo socioestructural, el sentido subjetivo de la acción ignorando los elementos del clima cultural, los encuadres institucionales y los condicionamientos sociales; los fenómenos de la vida cotidiana, el desarrollo del self o los procesos identitarios, las microinteracciones o la elección racional, la estructura del sentimiento $y$ de la personalidad, todo haciendo abstracción de la situacionalidad y los contextos sociales amplios en los que surgen, se desarrollan y sobre los que de vuelta reoperan. 
mundo; la sustancia devenida sujeto, Hegel). Contra el realismo ingenuo, el reconocimiento de que lo real no es transparente ${ }^{9}$; la función de la ciencia o de la teoría científica, según Marx, es penetrar la exterioridad empírica para descubrir la estructura relacional subyacente, trascender lo meramente dado, la apariencia engañosa (desfamiliarizar la relación con el mundo social), para captar las fuerzas no inmediatamente observables que generan las tendencias de movimiento de lo real, así como sus 'formas fenoménicas', que son también parte de ese real, que lo expresan y revelan a través de mediaciones ${ }^{10}$; que dejan de ser apenas una distorsión tan pronto como se las pone en relación o se reconstruye la relación en que están, con el proceso del que hacen parte, el proceso que son $y$ fuera del cual no significan.

Para ello, el método, desde Hegel, no puede ser concebido como exterior al objeto: 'el método no es, en efecto, sino la estructura del todo'; el método es el automovimiento de la cosa, una lógica concreta, que al no reducirse a lo formal — tampoco al 'trascendental' kantiano-, permite captar los contenidos, la dialéctica que encierran en sí, que impulsa la cosa hacia adelante; el método debe 'adaptarse al ritmo de la cosa misma' (el atomismo empirista no puede captar lo procesual). Por eso, para Hegel, la lógica es una onto-lógica, una lógica del ser y del pensar, cuyas categorías buscan captar la estructura y la génesis de lo real, no son simplemente nominales o convencionales, una ocurrencia más o menos ingeniosa. El sujeto, el pensamiento, construye el conocimiento de lo real, que no es como creían los empiristas clásicos un 'libro abierto'; solo la investigación y la reflexión crítica pueden darnos una aproximación a la estructura relacional no observable y 'este pensamiento es mi actividad', por tanto, 'esa

$9 \quad$ 'Si la realidad fuese transparente, no necesitaríamos ciencia', dice Marx, al poner las bases de lo que hoy llamaría una 'hermenéutica marxista'.

Que median y resultan de la relación dinámica de la estructura y el funcionamiento interno con el contorno cambiante, fuente de presiones y estímulos, adquiriendo la forma de adecuaciones con valor adaptativo. naturaleza es también el producto de mi espíritu, en tanto que sujeto pensante', infiere Hegel (2000, p. 22-23). La ilusión especulativa del genio idealista ${ }^{11}$, explicable, en parte por la distorsión inherente a las condiciones aparentes del trabajo en solitario del pensador individual (rasgo típico en la tradición dominante del oficio del filósofo y que contribuye a dar cuenta de la general inclinación idealista de esta), en parte por las condiciones intelectuales $y$ sociales de su época, lo lleva a pretender que el concepto, el sujeto pensante, puede agotar el objeto, eliminando la dialéctica de la relación, cerrándola. Es la consecuencia del racionalismo especulativo y del panlogicismo de Hegel. Pero ello no alcanza para atenuar el brillo de su monumental aportación, como inescapable base para el desarrollo posterior.

Para Marx y Engels se trata entonces, sobre la base de una justa apreciación del histórico cambio de perspectiva introducido por la contribución de Hegel, el método dialéctico, de apropiárselo, transformándolo en la base de toda investigación y reflexión crítico-racional de lo real. Esto quiere decir que el método es función del objeto y el objeto se construye teóricamente ( $y$ toda teoría tiene un fundamento y desarrolla premisas epistémicas). Una dialéctica materialista construye progresivamente sus categorías, siempre en tensión con el objeto, mediante las operaciones del sujeto, a través de los distintos tipos y niveles de abstracción (empírica, constructiva, reflexiva, Piaget (1972)), y considerando el momento histórico específico. Puesto en otros términos: el modelo teórico-metodológico, para aspirar a tener verdadero poder explicativo, debe intentar captar la estructura relacional y la lógica del movimiento de lo real, la complejidad y el devenir, reproduciéndolas en el plano de lo categorial, intelectualmente. Por ello para Marx y Engels, 'lo concreto es concreto porque es un resultado, la síntesis, de múltiples determinaciones', es un

11 Idealismo absoluto que por ello mismo está siempre a dos pasos del realismo, como dice Bloch y que permite entender que Engels y Marx hayan conseguido muy tempranamente redondear una completa reinterpretación materialista de la dialéctica, apoyándose en el Hegel 'ya casi-marxista'. 
concreto de pensamiento, no meramente percibido, constatado. Se parte de lo 'concreto' dado, inmediato, pobre en determinaciones, para ir más allá, negándolo y elaborándolo teóricamente, superando su abstracción mala (lo que está fuera del todo-proceso), para producir un verdadero concreto, resultado del pensar. Por supuesto, el juego de hipótesis resultante debe probar su valor empíricamente, en la práctica, como elemento central de una praxis racional, reproductora o transformadora.

En este marco se puede entender la central importancia epistémica de la categoría de totalidad y la especificidad de su formulación en el marxismo. En el rechazo de la categoría reside un típico extravío fundamental; quienes la adversan han buscado apoyarse en un argumento que se pretende rescate y afirmación de lo múltiple, de lo plural, de la diversidad. Uno de los insuperables problemas del pensamiento que procede mediante oposiciones polares es que se condena a no estar a la altura de la complejidad de lo real y por tanto, a no lograr más que una aproximación deficiente y a lo sumo de valor práctico-operativo, pero nunca científicoracional. Desde el punto de vista del marxismo, el tema pasa por la comprensión de que "fuera de la totalidad no hay diversidad, hay fragmento, $y$ el fragmento no significa'. Todo sentido supone relacionalidad, pero el fragmento, en su aislamiento, padece de una insuperable mala abstracción. Todo elemento de lo real existe en una conectividad estructural-dinámica; esa conectividad no puede ser una mera exterioridad, un rasgo secundario, un mero 'contexto'; la conectividad lo sobredetermina, lo define, lo produce; en últimas, cognitivamente, el 'elemento' es representado como un momento creado por el movimiento de la interrelación tensionada. A su vez, el momento reacciona con el todo relacional, contribuye a (re)producirlo, lo expresa.

La categoría de totalidad es epistémicamente decisiva e insoslayable porque permite o abre la posibilidad de captar la estructura de lo real, que es en sí misma relacional. Como todo objeto de conocimiento es una construcción, esto supone un recorte de lo real, una abstracción 'buena', aquella que supone una intervención cognitiva sobre lo múltiple aparentemente caótico; se abstraen aspectos de lo real para poder elaborar objetos de investigación, pero el trabajo del conocer no está completo hasta recuperar la concreción, es decir, la relación del objeto con lo real, con el proceso del que hace parte, $y$ fuera del cual no significa (el 'contexto' es su campo de sentido), pero ahora como un concreto 'rico en determinaciones', elaborado por el conocimiento, no meramente dado o percibido. Las totalidades elaboradas por el pensamiento son parte del proceso de construcción teórica del objeto cualquiera de estudio. Toda totalidad es una singularidad $y$ toda singularidad construida es un objeto complejo.

La categoría de totalidad es teórica y metateóricamente decisiva porque constituye una mejor aproximación que concepciones alternativas a la onticidad del objeto del conocer. Es el obstáculo que no han podido salvar las distintas versiones positivistas, formalistas o el fenomenismo; es la clave del notable éxito del sistemismo en general y del callejón teórico, sin salida, más allá de aportes parciales, de todo individualismo metodológico, de todo atomismo. Si lo real es una complejidad relacional en devenir, imagen que es una categoría del ser, entonces, las categorías del pensar deben tender a su reconstrucción intelectual, a ser su reproducción tan aproximada como sea posible en el plano del pensamiento. Y así, constituirse en la base y la herramienta racional-crítica de la actividad humana sobre el mundo.

Aunque se puede rastrear su presencia, en alguna medida, a todo lo largo de la historia del pensamiento, es desde fines del siglo XVIII que alguna versión de la conceptualización de la totalidad como elemento teóricometodológico viene imponiéndose, desde la arquitectónica del conocer racional de Kant y el romántico sentido de la organicidad, para alcanzar su mayor elaboración en el pensamiento de Hegel. Para Hegel, 'lo verdadero es el todo, pero el todo es proceso'. Es esta concepción de la totalidad dialéctica, relacional, unidad de opuestos o negativa, que se mueve y 'evoluciona por la propia dinámica de sus desequilibrios internos' y en interrelación retroactiva (positiva $y$ negativa) con el entorno, la que dará al marxismo su tono teórico-metodológico específico. 
Un todo particular (un objeto) resulta de la confluencia de elementos que, en la nueva circunstancia, supone el surgimiento de algo nuevo, una singularidad cuyas características y propiedades son emergentes, no estaban presentes en la situación anterior. La convergencia de los elementos, cualquiera sea la razón contingente, da lugar a algo nuevo. Una vez constituido, el todo particular alcanza un cierto equilibrio relativo y se torna el nuevo marco o matriz a partir de la cual se despliega una serie de eventos, la acción; se reproduce y desarrolla de acuerdo con una legalidad estructural característica, que expresa y determina los términos de la interacción de las partes y que da lugar a un funcionamiento regular; esto es, a una estructura estructurante, que siempre incluye tendencias $y$ tensiones desestructurantes y reestructurantes, movimiento que solo puede darse en y por la acción y la interacción.

Por tanto, lo que define al todo en general es su relacionalidad; 'el todo es más que las partes' porque es el resultado de sus interjuegos. Pero es la negatividad lo que distingue al pensamiento dialéctico de la totalidad, separándolo de toda noción simplemente holista (punto ampliamente trabajado por Engels en el AntiDühring) y de la mera relacionalidad circular. En los términos de Marcuse, lo que Hegel ha descubierto es una forma de dinamismo. Forma que es la base de toda génesis, de todo devenir real, en el que aparece lo nuevo. Lenin enfatiza en la negación como momento de la conexión, del desarrollo, a través de cuya mediación se mantiene lo positivo. La totalidad dialéctica es negativa porque es la unidad de opuestos, la combinación de lo desigualmente desarrollado, la articulación de diversas tendencias, a veces contrarias, incluso antagónicas; porque es la tensión entre lo real existente y los posibles; la lucha entre el statu quo y las fuerzas que tienden a modificarlo o a trastornarlo, en diverso grado. La negatividad es tensión, tendencia al desequilibrio y a nuevas combinaciones, lucha entre opuestos, $y$ es por tanto, la fuerza motriz del proceso ${ }^{12}$.

12 La dialéctica de positividad/negatividad, separa $y$ distingue al marxismo de toda visión centrada
La conceptualización del devenir-génesis se completa con la tematización de la interacción del objeto con las condiciones de contorno. La singularidad-totalidad metaboliza con el medio circundante en un circuito de realimentación, a diferentes niveles de complejidad. Finalmente, es a partir de los puntos de conexión, de afectación, entre la dinámica interna y la relación con la exterioridad, del resultado de ese choque-articulación, que se puede estudiar y captar el movimiento general del proceso, así como comprender que en momentos críticos se comporte o se mueva en forma no-lineal.

Totalidad $y$ negatividad son inseparables en la visión marxista, y se encuentran en la base de su perspectiva epistémica, lo cual pone al marxismo en línea con las más avanzadas corrientes del pensamiento contemporáneo, las que se apoyan en las categorías de complejidad y devenir. Es lo que permite que la teoría y el método del marxismo sean el fundamento, sólido y consistente, de todo pensamiento social crítico.

Basados en lo anterior, se puede avanzar sobre algunos aspectos fundamentales de la concepción marxista de lo social y de la teoría social. Partiendo de las categorizaciones más generales, en ontología y teoría del conocimiento, el marxismo puede ser definido, en el estudio de lo social, como un análisis crítico del capitalismo en el marco de una teoría materialista de la historia o bien, como una teoría de la totalidad social fundada en un análisis de economía política. Apoyada en una determinada base de riqueza material $y$ en unas específicas relaciones sociales de producción, la totalidad social articula y jerarquiza una diversidad de dimensiones $y$ esferas con distinto nivel de autonomía, que interactúan y se afectan recíprocamente, dando lugar a la historicidad, el movimiento, de lo real social.

exclusiva o preferencialmente en lo positivo, típicas de todo descriptivismo empirista o exterioridad fenomenista. Todo está mediado o es mediación, $y$ esto se entiende porque 'toda determinación es una negación', como sabía Spinoza, y la negación da lugar a una nueva positividad. La base de todo esto la da Hegel al exponer la lógica del devenir, en el cual el ser pasa al no-ser, pero el no-ser no es la nada y su vacío, sino algo otro, lo que pasa a su otro; lo negativo media la sucesión de positividades. 
Así, el marxismo se opone por el vértice a la multiplicidad desjerarquizada $y$ deshistorizada típica del hiperempirismo postmoderno. Como las estructuras no hacen la historia, sino los seres humanos, porque 'la historia no es nada más que la actividad de los hombres en la prosecución de sus fines' (Engels y Marx, 1978), el concepto de praxis es la piedra angular de la concepción de lo histórico-social. Obligados a actuar asociadamente para proveer a sus necesidades $y$ subsistir, siempre en lucha con un inclemente entorno natural, una criatura (que ha devenido) inteligente, capaz de problematizar y elaborar mentalmente su relación con el mundo (de aprender de la experiencia y modificar su conducta - relación con el medio- en consecuencia), gradualmente (a través de toda suerte de vicisitudes históricas) opera modificaciones de distinto orden en ese medio natural, modificaciones que, de ser exitosas, se constituyen en ambientes más favorables para el desarrollo de la vida humana, lo cual por su vez da lugar a un conjunto de efectos, - - buscados o no-, como: reducción de la carestía, consolidación y expansión demográfica, difusión territorial y sobre todo, diferenciación de la vida social y de su elaboración cultural. Una relacionalidad social más elaborada, con nuevos recursos instrumentales y capacidades culturales/mentales, incrementa por su vez las posibilidades de la praxis/intervención. Localmente, tales posibilidades pueden o no actualizarse, pero tomando en conjunto el itinerario humano, efectivamente han encontrado una cierta forma de realizarse. Es a lo que se refiere en retrospectiva como 'evolución cultural'.

El hecho de que la evolución social se haya movido en la dirección de una creciente complejidad relacional, desplazando la frontera de las posibilidades culturales e incrementando los niveles de consciencia y autoconsciencia, ampliando espectacularmente tanto las opciones de desarrollo individual como el mismo concepto de condición o 'naturaleza' humana, todo sobre la base de una extraordinaria expansión en la infraestructura de riqueza material y del conocimiento técnico, da definitiva cuenta del carácter decisivamente central de la categoría de praxis social. En la praxis, los seres humanos constituyen tanto el mundo como su subjetividad.

Praxis es una categoría analítica central en el marxismo. Pero sigue siendo parte de una sistemática conceptual, no es absoluta. Algunos teóricos parecen haberse excedido en su elaboración del concepto, como una reacción, muy probablemente, a los correlativos excesos del objetivismo histórico y eso ha producido deslizamientos hacia cierto humanismo subjetivista, o variantes de voluntarismo $y / 0$ relativismo. Tales énfasis han contribuido sin duda a profundizar determinados temas en el marco de la perspectiva marxista; sin embargo, continúa siendo necesario reintegrar tales contribuciones en un concepto general más satisfactorio.

La praxis genérica, creativa $y$ autocreadora, es la acción intencional sobre el entorno del individuo social, en un particular contexto histórico de límites y posibilidades, para ajustarlo a sus necesidades $y$ deseos; la actividad a través de la cual el hombre cambia el mundo dado $y$ produce un mundo social objetivo, su medio, que por su vez induce cambios en el ser humano mismo. Tal actividad vital es genérica, comparada con la de los animales no-humanos, porque se da en relación con una estructura de las necesidades no fija, que desde el principio tiende a hacerse incomparablemente más amplia y sofisticada, porque tiende a liberarse, modificándolos en profundidad, en su carácter $y$ en la forma de satisfacerlos, de los aspectos más directamente biológicos; $y$ por ello se hace capaz de crear 'también según las reglas de la belleza' (Marx, 1980) ${ }^{13}$.

Este proceso de autoproducción y autoorganización se da durante la mayor parte de la historia hasta muy recientemente, de una forma estrechamente práctica, acercándose gradualmente y acelerándose a partir del ascenso de la burguesía como clase social, a una actividad racional, de carácter instrumental, como

\footnotetext{
13 "El animal forma únicamente según la necesidad y la medida de la especie a la que pertenece, mientras que el hombre sabe producir según la medida de cualquier especie $y$ sabe siempre imponer al objeto la medida que le es inherente; por ello el hombre crea también según las leyes de la belleza" (Marx,1980, p 112).
} 
parte de las condiciones para alzarse a una verdadera praxis racional, teórico-críticamente informada e históricamente consciente.

Es desde este punto de vista, de la creciente capacidad de los seres humanos para modificar las circunstancias según sus necesidades $y$ deseos — que tienden correlativamente a sofisticarse con cada logro-, de una elaboración racional cada vez más potente, que es efecto y causa del proceso, que se afirma en el marxismo que 'la vida social es esencialmente práctica' (Marx). Pero una praxis que tiende a ser y que debe ser cada vez más social e históricamente consciente y racional.

Entonces, una teoría de la totalidad social es un estudio del ser humano relacionado con su entorno social, pero ese medio es una realidad histórica objetiva, legada por la actividad humana pasada, cuyo presente, a su vez, es el de un mundo dado y un ámbito de posibilidades, de cursos probables: lo real existente es un momento de lo posible, es el resultado de una particular combinación de posibles en el momento previo. Razón por la cual ningún fenomenismo, ningún empirismo, formalismo o variante de individualismo metodológico, puede dar una teoría o un modelo explicativo satisfactorio de lo real social, más allá de aportes puntuales.

Todo objeto dado está mediado o es mediación, es decir, es resultado; de lo cual se sigue la reconstrucción de la legalidad estructural que lo ha producido. Tal 'estructura', tomada en el sentido de Piaget, como sistema de transformaciones, puede ser representada como articulando dimensiones diversas $y$ de diversa entidad, de lo social, a saber, lo económico, lo político, la estructura de clases y grupos sociales, lo cultural-ideológico o por los valores, normas, instituciones, y la acción social colectiva o individual que las crea, reproduce o pone en cuestión, etc. Lo real social es entonces una complejidad relacional en devenir, una multidimensionalidad organizada, jerarquizada, en último término determinada, totalizada, por la producción y reproducción de la vida material, las condiciones concretas de la existencia. Pero como bien alerta Engels, esto no implica cualquier asomo de reduccionismo, pues cada uno de los factores o dimensiones concurrentes disponen de cierto margen, variable, de autonomía (no de independencia, lo cual rompería la unidad negativa, de opuestos, el automovimiento) $)^{14}$. En cada momento histórico, una específica combinación de factores está detrás del aspecto exterior, produce una fenomenización de lo real, su aspecto positivo, así como su ritmo, en equilibrio relativo o cambio acelerado.

Manteniendo entre paréntesis la relación con el entorno, la totalidad social se mueve internamente a partir del entrejuego, la interrelación de los diversos componentes, que son a su vez subsistemas, subprocesos, singularidades complejas, desigualmente desarrolladas, cuya combinación, la 'combinación de lo desigualmente desarrollado' (Trotsky, Novack y Moreno, 1977), justamente da lugar al movimiento de la totalidad o movimiento de totalización (de diferenciación-integración -Piaget-, contenido del devenir-génesis); automovimiento que (reconectado ahora con la paralela e ineludible relación del sistema con el medio del que hace parte, del que ha surgido, en fin de cuentas, $y$ con el cual permanentemente metaboliza; relación que por supuesto implica que lo interno y lo externo solo pueden separarse temporalmente para los efectos del examen analítico de lo particular) abordado por el conocimiento, puede dar lugar a una representación conceptual comparativamente satisfactoria, por aproximaciones sucesivas, del carácter y el comportamiento efectivo de lo real, lo cual a su vez permite avanzar en la comprensión del

$\overline{14}$ "Según la concepción materialista de la historia, el factor que en última instancia determina la historia es la producción y la reproducción de la vida real. Ni Marx ni yo hemos afirmado nunca más que esto. Si alguien lo tergiversa diciendo que el factor económico es el único determinante, convertirá aquella tesis en una frase vacua, abstracta, absurda”(Engels y Marx, 1971). El autor continúa afirmando que si bien la situación económica es la base, los distintos factores de la superestructura, desde el sistema legal hasta las teorías políticas, filosóficas y las ideas religiosas, ejercen también su influencia sobre el curso de los acontecimientos "y determinan, predominantemente en muchos casos, su forma”. 
movimiento de ese real, $y$ en particular del surgimiento de lo nuevo, problema de los problemas de una epistemología dialéctico-genética, condición de posibilidad de todo pensar crítico y única capaz de romper consistentemente con una visión positivista (atomista, fenoménica, estática, formalista, lineal), incorporando críticamente sus aportes.

La totalidad negativa constituye el elemento central del modelo epistémico de la teoría marxista. Sobre la base de esta articulación-jerarquización de la multiplicidad existente, se torna factible acometer una reconstrucción intelectual empíricamente controlable de lo real social. En otros términos, se está aquí frente al problema general de la relación teoría/investigación empírica. Si se parte de que el hecho no está dado, se construye, de que toda observación está teóricamente cargada, de que si bien la teoría sin praxis es vacía, la praxis sin teoría es ciega, se puede entonces hacerse cargo del hecho de que lo real puede ser abordado de diversas maneras, siendo algunas más satisfactorias cognitivamente que otras. En el conocimiento de lo social han concurrido, en la historia de las ideas de los últimos dos siglos, diversas propuestas teóricas, estableciéndose entre ellas una relación de competencia y afectación recíproca. Se ha dicho reiteradamente que Durkheim y Weber realizan su trabajo siempre en lucha con el fantasma de Marx.

A su vez, el marxismo - en sus diversas líneas de desarrollo- $y$ en lo que puede ser designado como su corriente central, ha ido de una forma $\mathrm{u}$ otra incorporando aportes provenientes de los más distintos y distantes orígenes. Lo que en realidad lejos de ser una novedad está en la génesis misma del marxismo, como punto de encuentro y de reelaboración y síntesis original de lo mejor del pensamiento y la investigación, pasados y presentes. De la inagotable riqueza del pensamiento filosófico clásico hasta Darwin y la naciente Antropología, pasando por la gran eclosión del conocimiento científico de la modernidad y la gran filosofía de la era burguesa, el marxismo - dígase con rotundidad- surge, se desarrolla y solo tiene futuro, si se muestra capaz de mantener su capacidad y disposición de interlocución crítica con lo mejor del pensamiento y la investigación, heredada y contemporánea. Nada tiene que ver con el marxismo, con sus fundamentos y espíritu, la noción de una doctrina autosuficiente. El marxismo es abierto o no es. Pero, por supuesto, tal apertura se da en el marco de una intransigente defensa de la actualidad de sus fundamentos como teoría y método de un pensar crítico, sobre la base de la permanente puesta a prueba de su poder explicativo, valor heurístico y premisas epistémicas.

Desde el punto de vista del marxismo, el encuentro con la Sociología, el primero concebido como teoría de la totalidad social, la segunda como ciencia de la sociedad ( $y$ del desarrollo social), se da entonces en un campo teórico-metodológico que busca articular dialécticamente una concepción de lo históricoestructural con una teoría de la acción, relación mediada por lo cultural. Como se ha dicho, contra todo extravío irracionalista o fenoménico, tal conceptualización se apoya en un análisis de economía política, la cual, como dice Marx, en el Prefacio de la Contribución a la crítica de la economía política, da la anatomía de la sociedad. Pero solo la anatomía, pues los elementos de la superestructura, en su diverso grado de autonomía, resultan por su vez fundamentales para la reproducción del mundo social, en su forma y ritmos, en tanto retroactúan con la estructura subyacente.

Como marco teórico, el marxismo ha ido construyendo, en tensión crítica con otras corrientes de pensamiento, una reelaboración interpretativa de los datos y hallazgos de la Sociología, relacionados con el objeto de estudio más complejo, lo humano-social ${ }^{15}$. Un aspecto

15 Tal complejidad es lo que da lugar a la proliferación de disciplinas y estudios especializados en el ámbito de lo social, lo que a su vez ha generado el problema de la compartimentación del conocimiento construido, el cual adolece comprensible e inevitablemente de las limitaciones propias de una exploración que, si bien ha producido un enorme y valioso acervo, exhibe muy clara y hasta dramáticamente, las consecuencias, en forma y contenido, de la debilidad o total ausencia de un igualmente necesario momento paralelo de generalización e integración de avances particulares, en la perspectiva del curso histórico-social de conjunto; un 
central para entender la relación individuo/ sociedad reside en la mediación cultural ${ }^{16}$. La noción de cultura es objeto de un prolongado desacuerdo en el pensamiento social; un desacuerdo que tal como se presenta sintomatiza los problemas teórico-metodológicos no resueltos de las disciplinas de lo real social. El marxismo (contra todo subjetivismo, pragmatismo, formalismo, fenomenismo o fragmentación de lo 'plural') pone un fundamental criterio histórico-crítico de inteligibilidad. La cultura (como dimensión de la totalidad social, de 'la sociedad') y la producción cultural, está en estrecha relación con —es condicionada por- la forma histórica específica de organización social de la producción material de la existencia, de las condiciones de vida, con la cual a su vez y desde ahí interactúa, funcionando con un grado variable pero siempre relevante de autonomía. Se propone así una comprensión/explicación histórico-materialista de las interrelaciones entre las ideas y las condiciones concretas de la existencia en y desde la praxis humana (base de la sociología del conocimiento y dimensión/ categoría que permite superar los impasses

resultado del pensar indispensable para las posibilidades de una construcción social y un autoproducirse humano conscientes.

Una elaboración satisfactoria de la conexión dinámica de lo macro y lo micro, de lo objetivo y lo subjetivo, de 'sistema' y 'mundo de la vida', etc., es algo que dada su evidente $y$ crucial importancia ha sido perseguido por diversos estudiosos, dentro $y$ fuera del marxismo. Autores de referencia como Giddens y Habermas, Wallerstein o Elías, Kofler, Adorno, Heller, Lefebvre, Bourdieu o Goldmann, abordaron el asunto en un sentido $\mathrm{u}$ otro. Se trata de un tema aún abierto y particularmente arduo, sobre el que continúa el debate, incluso dentro del marxismo. Pese a ello, la mayor parte de los estudiosos marxistas estaría de acuerdo en que el problema, tal como puede observarse en los fundadores, debe ser afrontado mediante una articulación dialéctica de una teoría de la dinámica socioestructural y una teoría de la acción. El abismo indeterminista es incluso un retroceso respecto de la vía muerta del determinismo mecanicista o del materialismo vulgar; solo el reconocimiento de la capacidad de los seres humanos para conocer $y$ transformar racionalmente el mundo, puede despejar las vías para la construcción de una teoría satisfactoria de la sociedad y el desarrollo social. paralelos del idealismo/subjetivismo y del materialismo vulgar). La cultura y los productos culturales surgen de $y$ en la actividad humana asociada al entorno físico, orientada a la satisfacción de necesidades (biológicas, psíquicas y sociales-comunicativas) y como mediaciones necesarias para esa satisfacción. Así, la cultura surge de la praxis, es praxis, y la praxis está, de vuelta, crecientemente mediada $y$ desarrollada por la cultura, es cultura.

Desde una perspectiva sociológica general, los productos humanos de determinado estadio de la evolución social (del colectivismo tribal al capitalismo globalizado), el conjunto de objetos o recursos, tangibles o intangibles (las creencias, artefactos e instituciones, en la fórmula de Malinovski), elaborados socialmente por los individuos que median sus interacciones, su funcionamiento y conducta social, así como sus relaciones, su metabolismo, con el entorno natural a fin de atender sus necesidades $y$ aspiraciones, en las condiciones generales de escasez, el reino de la necesidad, que han imperado a todo lo largo de la historia humana hasta el presente, es lo que las principales corrientes del marxismo conceptúan como cultura.

En las condiciones más específicas de la civilización de clases, las formas culturales imperantes, construidas por los hombres, pero en condiciones institucionales surgidas de la explotación del trabajo humano, la dominación $y$ las distintas formas de opresión, han servido para regular y controlar ('disciplinar'); así como hacer previsible el comportamiento y convivencia de los subordinados, construyendo consenso e integración social funcionalizada hacia la masa plebeya (despolitización y debilitamiento de la capacidad de resistencia, atomización y conformidad). En el marco histórico definido por la división y el conflicto de clases, las tradiciones, costumbres, instituciones y el sistema significante-representacional predominantes, tienden a expresar la estructura y dinámica del orden social reinante, operando en su reproducción, regulación y ajuste, generando las condiciones ideológicas y situacionales de su interiorización naturalizada por los individuos, sobre todo los más jóvenes, en el proceso de socialización, de desarrollo de las identidades 
colectivas e individuales (de las creencias, ideas, valores, hábitos, el sentido común, representaciones y mentalidades) ${ }^{17}$.

De manera más directa, la cultura dominante es en cierto sentido "una gigantesca empresa de elaboración de estrategias de contención del conflicto", por la vía de entorpecer su desarrollo consciente, de la conciencia para sí de los explotados y oprimidos. De ahí la imperiosa necesidad de saturar la superestructura cultural, en sus diversos niveles y ámbitos, con valores $y$ representaciones que orienten a pautas de conducta, culturas de consumo, estilos de vida y expectativas funcionales e integradoras. La generalizada mercantilización del clima $y$ la producción culturales tiene como resultado la pérdida de potencial crítico, el desarme, la neutralización y la cooptación de expresiones artísticas inicialmente venidas con un fuerte talante transgresor ('la cultura, como el sexo, se hace más asequible, pero de una forma degradada') (Marcuse,1969).

Es decir, para el marxismo, un marco teórico-metodológico para avanzar en la construcción del concepto de cultura articula, en torno a la praxis social, dos niveles del problema: por un lado, la función de los marcos culturales en la mediación y regulación del funcionamiento y reproducción de la macrosocialidad, y en los distintos planos de la interacción social, integrada o conflictiva; por otro lado $y$ en un rango histórico más amplio, el papel de lo cultural en el proceso evolutivo, como principal instrumento adaptativo de una criatura inteligente. En otras palabras, lo primero tiene que ver con la mediación de la interacción, en

$17 \quad$ Las estructuras culturales aparecen entonces como el contexto general de socialización, de desarrollo de las identidades grupales y de la autorepresentación; como el modo de vida general, en el cual surgen y se desarrollan, en el aprendizaje cultural, modelos de comportamiento, los hábitos $y$ costumbres, que distinguen como grupo a cada comunidad. Las mediaciones culturales resultan de la interacción y favorecen esa interacción; esa interacción se da en y responde a determinadas condiciones objetivas de la existencia, que a su vez, la acción social y la consciencia pueden alterar. En ese marco, el estudio de la función simbólicacomunicativa de los recursos culturales. general y en las condiciones concretas de la sociedad de clase. Lo segundo, con el despliegue histórico de la subjetividad, de la consciencia, en la exterioridad social (que es su actividad y su producto; el 'espíritu objetivo' del idealismo alemán) y su materialización progresiva en las instituciones humanas.

Lo cultural se relaciona entonces con el papel de la subjetividad — crecientemente consciente- $y$ sus objetivaciones, en la vida social, estructura y devenir. Esto conecta directamente con una de las nociones centrales de cualquier sociología, los procesos de socialización. La diversidad de mecanismos mediante los cuales una comunidad cualquiera busca asegurarse la integración funcional de los individuos, desde el inicio y a todo lo largo de su vida, pone el marco en el que pueden darse los procesos psicosociales de desarrollo de las identidades individuales y colectivas (los grupos sociales en los que participa el individuo cumplen un papel principal). Las estructuras culturales funcionan, entonces, como el contexto desde el que puede darse la interiorización de los aspectos formales $y$ de contenido, valores y normas, relaciones sociales $y$ arreglos institucionales, usos y creencias, costumbres y tradiciones, que operan en la reproducción del orden social y que pueden hacer predecible el comportamiento dentro de un rango de variación institucionalmente tolerable y moldear las actitudes, entendidas como 'predisposición aprendida a responder de un modo consistente a un objeto social' 18 .

Presentar la socialización como un proceso de desarrollo identitario de 'aprendizaje de normas $y$ valores culturales, $y$ de convertirlos en parte del propio yo interior', sin más -al margen del contexto social y los marcos culturales, de las presiones y hasta la coerción, de la situacionalidad y los términos de la interacción o grupos de pertenencia de los individuos- es vaciar de contenido y de sentido el concepto, al negligenciar la referencialidad material y práxica. El típico extravío idealista

18 La presión cultural difusa pero ubicua de la comunidad, la une con la tradición. 
que pretende pensar la subjetividad en desconexión con las interacciones autoorganizadoras con el medio social.

Piaget ha producido toda una obra que estableció con rotundidad y como base para desarrollos y precisiones posteriores, que el proceso de aprendizaje no se reduce a la asimilación de informaciones del exterior, sino que los sujetos jóvenes elaboran activamente sus experiencias, siempre en relación con el nivel alcanzado en el desarrollo de los esquemas de razonamiento. El Yo interior no es un reflejo simple de las expectativas sociales $y$ los reclamos culturales, es una construcción interior al individuo, la cultura no es una mera imposición sin mediaciones intrasubjetivas. En el proceso de conocer, todo nuevo conocimiento es asimilación a esquemas previos, y estos esquemas cognitivos consisten $y$ surgen (psicogénesis) de la interiorización de la estructura de rasgos generalizables de la acción; es decir, que si los esquemas dan a los individuos la capacidad de formular sus representaciones, estos esquemas surgen en la interacción de los sujetos con su medio. Estos esquemas cognitivos se constituyen inconscientemente (el 'inconsciente cognitivo').

La socialización supone que el individuo, situado en un determinado contexto social y en interacción con ese medio, va formando unos esquemas cognitivos que seleccionan y procesan su información, que filtran y configuran lo que él va a aceptar como la realidad, como el mundo (Martín-Baró, 1992, p.119).

La cultura no es una simple imposición $y$ las personas tienen cierto margen, variable según los antecedentes sociales (el 'lugar social de origen' y las oportunidades de vida que tiende a imponer), para interpretar los rasgos $y$ producciones culturales que incorporan, pero esto se da en contextos de interacción de los diversos planos de la vida social. Esos marcos de interpretación son un resultado de la experiencia social, incluso si en su desarrollo personal, el individuo se desmarca de los códigos dominantes de interpretación. El Yo, entonces, media y se desarrolla en la mediación, entre las demandas del mundo social y las inclinaciones neurobiológicas (la pulsionalidad), apoyándose en estructuras cognitivas de asimilación, $y$ es este Yo el que construye conocimientos y realiza elecciones, en su relación con el entorno. El Yo sin contexto y sin historia es una ficción inútil y mistificante.

El proceso de socialización es el proceso de integración a la sociedad, a los roles que la posición social objetiva prescribe. Un medio social rural modela a las personas para su papel de campesinos (las condiciones sociales estructuradas por el mercado moldean tipos humanos que tienden a naturalizar tales condiciones). Los modela física y espiritualmente (hay una construcción social y una modelación cultural de la sensibilidad; incluso, aquello que en determinado tiempo y lugar social puede usualmente provocarnos sufrimiento psíquico o rechazo moral, está culturalmente codificado y es instilado en la relación con los otros). En la medida que las estructuras o instituciones del medio social son fuente de estímulos inductores a la integración, la socialización opera interiorizando estas fuerzas, hasta lograr la representación naturalizada del ordenamiento. Así, el individuo va asumiendo, desde la más temprana edad, el comportamiento y el desarrollo personal esperado por la comunidad, hasta que se torna un 'desde dentro', un 'por sí mismo', 'voluntaria $y$ libremente'; nadie, aparentemente, se lo ha impuesto, él, incluso, lo ha buscado y hasta deseado. Todos y cada uno de ellos se sienten sujetos de su acción, todos se refieren a sí mismos como 'yo' (Martín-Baró, 1992).

De esta manera, la 'persona' efectivamente surge en la socialización, pero una 'persona' que emerge a partir de este proceso sociohistórico concreto de configuración (contra el disparate teológico-metafísico); va surgiendo en relación con las expectativas sociales institucionalizadas que la rodean; en la relación con los otros individuos del contorno y grupos de los que participa, que ejercen presión -coactiva $y / 0$ seductora-y que lo hacen siguiendo los códigos (normas, valores $y$ creencias culturales) que por su vez han interiorizado y que han asumido como 'naturales', no como históricos, esto es, producidos, cambiantes y modificables. Desde ahí pueden 
entonces actuar, 'los otros', como factores de socialización de los individuos. Así, 'la sociedad' no es algo mecánicamente externo a la identidad de la persona, es su elemento configurador principal; está en la personalidad. El individuo construye sus experiencias y vivencias en un campo social concreto, al interior de un mundo objetivo de relaciones interpersonales. La sociedad se interioriza. El sujeto es integrado, cuando la socialización es exitosa.

El individuo puede sobreponerse a las tendencias, pero eso requerirá grandes esfuerzos, fuerza mental, capacidad de resistencia ante los obstáculos y fracasos parciales, entre otros. Luchar contra la corriente no es imposible, pero las posibilidades de éxito han de enfrentar la tendencia de todo orden social a la autoconservación, y en todo caso, el éxito depende de la efectiva presencia, socialmente construida, de opciones reales o al menos de condiciones que ofrezcan la posibilidad objetiva de crearlas. La acción y sus opciones efectivas, están en relación con un horizonte de posibilidades reales históricamente producidas. El mundo que habitamos es un legado de generaciones anteriores $y$ de nuestra propia acción. El mundo es praxis histórica y presente. La acción individual y de pequeños grupos alcanza eficacia social en la acción social colectiva; la asociación de individuos con interpretaciones compartidas sobre sus intereses e identidades (conciencia de clase) puede dar lugar a movimientos sociales capaces de influir decisivamente sobre el curso de los acontecimientos, de desencadenar cambios sociales efectivos. Pero, otra vez, todo esto se da contra la resistencia de lo constituido. Es una lucha.

En los textos convencionales sobre socialización, los abrevados en la tradiciones culturales liberales norteamericanas particularmente, aparece muy claramente el interés en reducir el peso de las circunstancias y contextos en la explicación del desarrollo identitario, enfatizando verbalmente (para después subordinarlo muy concretamente a fuerzas ciegas, como el mercado fetichizado o algún determinismo genético) el margen discrecional de los individuos y la libertad para interpretar los elementos de la cultura que adoptan, $y$ para decidir cuáles roles les gustaría asumir y cómo los representarán a su manera particular'. Más allá del afán de coherencia respecto del clima ideológico-cultura liberal tradicional, tal operación rompe la dialéctica del proceso (la libertad no es la ausencia de condicionamiento, sino la capacidad para reconocerlo, como parte de una acción transformadora, consciente y racional; superar la necesidad, humanizando el mundo), y tarde o temprano el relato se contradice, tiene que, dada su ostensible falta de realismo, llegando incluso a describir situaciones con un grado de condicionamiento que comienza a parecer excesivo; dependiendo del tema, estos textos pueden oscilar, sin solución de continuidad, entre un construccionismo sin anclajes y un "sociologismo" sospechoso de coartada social, eximidora de toda responsabilidad personal. Generalmente esta diferencia se observa cuando se pasa de consideraciones generales (subjetivismo de la libre elección) al estudio de casos concretos (objetivismo de las estructuras modeladoras de actitudes y gustos). Es el costo de ignorar la dialéctica de los procesos complejos en lo real, efecto y causa de desdeñar la dialéctica como método.

Tras lo señalado, no hace falta mucho más para entender los mecanismos y funcionalidad del proceso de socialización bajo las condiciones de una sociedad de clases, fundada en la explotación y apoyada en distintas opresiones. La condición general de clase resulta un marco estructural central en la socialización.

La mayoría de los adultos acaban en la misma clase social en que nacieron... ¿Porqué los sueños y el trabajo duro no son suficientes para que la mayoría de la gente trabajadora alcance la vida a la que aspiran? Algunos aspectos de la estructura social, como el acceso a la educación y las oportunidades en el mercado de trabajo, juegan un importante papel. Pero también la socialización tiende a canalizar a los niños de diferentes clases sociales por los mismos caminos de sus progenitores. Una parte importante de esta socialización por clase social es la transmisión de valores (Light, 1991, p.124). 
El hecho de que los hijos de la burguesía $y$ de la 'clase media alta' (profesionales con educación universitaria $y$ altos salarios, $y$ medianos propietarios) realicen un aprendizaje cultural $y$ de roles que naturaliza su posición social privilegiada y los prepare - necesite prepararlos-, para asumir la tarea de perpetuar tal condición, los separa muy claramente de todos los demás jóvenes. Por su parte, los sujetos provenientes de los estratos de calificación media y baja del proletariado ('todo aquel que para vivir depende de la venta de su fuerza de trabajo, manual o intelectual'), son preparados, por todo su entorno $y$ en particular por sus propios padres, a partir de su concreta experiencia de vida, para interiorizar rasgos que implican conformidad con la autoridad externa ('ética laboral') —en detrimento de aspectos como 'autonomía', 'creatividad', 'pensamiento independiente'-, como precondición para la aceptación de una vida de trabajo rutinario $y$ mal pago.

Resulta evidente que en una sociedad compleja y altamente diferenciada, el proceso de socialización debe atender distinciones de clase y ubicaciones en la jerarquía social cada vez más diversas y sutiles. En una misma condición general de clase, pesan aspectos diferenciadores como lo urbano/rural, carácter más o menos cosmopolita de la actividad, acceso a bienes culturales más o menos sofisticados, el vecindario, el tipo de experiencia escolar, así como, la relación con otras categorizaciones sociales, la condición étnico-racial, de sexo-género, laicidad, entre otros. Lo central entonces es que la posición en la jerarquía social y el marco cultural correspondiente, induce roles, identificaciones, formas de ver, aspiraciones, rasgos psicológicos, una estructura de la personalidad y el sentimiento.

Si praxis es el concepto angular de una teoría sólida de lo histórico-social, como expresión concreta de la relación de la subjetividad con la objetividad, el mundo, el estudio de los procesos de socialización funciona como un importante insumo para entender los mecanismos y recursos de poder desde los cuales se moldea el carácter y constreñimientos de esa praxis social, en las condiciones de la sociedad de clases. Esa articulación conceptual abre el camino para los estudios sobre vida cotidiana desde el marxismo ${ }^{19}$. Se trata de otra noción pendiente de un acuerdo conceptual suficiente. Como aproximación, por 'vida cotidiana' se entiende el ambiente inmediato de la existencia social del individuo, con sus actividades y vivencias, en el marco de la socialización recibida, la interacción culturalmente mediada, la relacionalidad social general y la posición en la jerarquía social.

Comprender los microprocesos, articulaciones y el ritmo de la vida cotidiana resulta decisivo porque es en tal ámbito que se 'vive' el orden social institucionalizado y por donde pasa parte de la reproducción de la globalidad social. En la cotidianeidad se expresan condensadamente, subjetivamente interiorizadas, desde una experiencia individual, todas las fuerzas modeladoras de la estructura y dinámica de la totalidad social. La cotidianeidad de los diversos individuos es la totalidad social en su múltiple inmediatez, la prácticamente ilimitada fenomenización positiva de lo histórico-social, su realización en un tiempo y lugar determinado (el todo desplegado sobre su amplia potencialidad de momentos particulares; 'lo real-existente como momento de lo posible'). Lo cotidiano es un resultado, provisional y frágil, pero repleto de significación. Pero es también un ámbito en que se desarrolla la reproducción de lo macro-social. 'Lo social se explica por lo social, pero pasando por lo interindividual'; las estructuras no hacen la historia, solo los individuos, inmersos en tramas relacionales y marcos culturales, componiendo formas de acción colectiva, pueden reproducir o modificar sus propias condiciones de existencia. Parte de esto pasa por la vida cotidiana.

La cotidianeidad es el medio en que nos movemos diariamente, que nos resulta familiar $y$ que conocemos de manera fundamentalmente práctica, en el que realizamos diversas tareas $y$ atendemos necesidades que resultan imprescindibles para nuestra forma personal de vida,

19 En nuestro medio, George García ha realizado una contribución notable y de referencia obligada sobre el tema. 
aunque normalmente al ser percibidas como parte de lo ordinario y tomadas en forma separada, su valor se ve reducido. En sus versiones más sólidas, la noción incluye el conjunto de actividades, creencias de sentido común, sentimientos, usos y costumbres, así como artefactos, mediante los cuales los individuos, sumidos en sus actividades privadas, reproducen sus condiciones de existencia inmediatas, y lo hacen conscientemente, tomando decisiones y realizando elecciones. Una acción finalista, deliberada, en cierta medida, pero repetitiva, estructurada para solventar diariamente, sin necesidad de mayor reflexión, la conservación/reproducción de lo existente, de lo "normal", la representación de lo habitual en la que apoyamos toda la estructura de la vida a la que estamos acostumbrados. Una vida que suele ser poco gratificante (incluso desestimulante, o fatigosa, física y psíquicamente, en las condiciones sociales y laborales imperantes en la vida urbana bajo el capitalismo), pero que gracias a la capacidad para incorporar pragmáticamente lo cotidiano se le puede experimentar con las ventajas psicológicas de la rutinización (economía cognitiva y cierta reducción del grado de ansiedad que provoca la inevitable, si bien muy variable según la posición social, incertidumbre vinculada con nuestro estar en el mundo).

Es un microcosmos en el que se objetivan $y$ articulan de modo subjetivamente particular las estructuras, oscilaciones y tensiones del orden social, movimientos ante los cuales los individuos, familias o pequeños grupos, no pueden más que reaccionar ajustando sus comportamientos a fin de contrapesar las presiones. En general, la vida cotidiana funciona (o se espera que funcione) como el reino de lo rutinario, de la estable realidad objetiva inmediata de los individuos y de su forma de percibirla. Pero sería más preciso afirmar que el mundo de la vida diaria se ve sometido a una constante oscilación entre la rutinización subjetiva, derivada de la regularidad tendencial y la siempre acechante 'ruptura de la normalidad', inducida la mayoría de las veces desde un ámbito exterior a la cotidianeidad. Las vicisitudes personales constantemente excitadas por los problemas sociales de que derivan y de los que mayormente no tienen conciencia los individuos.

Un aspecto fundamental de la estructura y el flujo de lo diario, es el pensamiento de sentido común. Conjunto de esquemas interpretativos, de representaciones sobre la realidad (instrumentos cognitivos $y$ valorativos), sobre los distintos asuntos del universo que se habita, desde el mundo natural y la sociedad hasta creencias en lo trascendente o convenciones morales, las relaciones afectivas, los gustos $y$ las prenociones, principalmente lo que de alguna manera se cruza en su vida - o está presente en su entorno, como representación colectiva, sin necesidad de experiencia directa personal-, desarrolladas inconscientemente por los individuos, en el seno de los mecanismos socializadores, de las que dispone cada uno para encontrar un cierto orden en el mundo en que se mueve, orientando $y$ dando sentido a su cotidianeidad, que constituyen el contenido básico de la acción intencional de la mayor parte de las personas en su vida diaria. Esta función de orientar la mayor parte de las acciones humanas (auto)representadas como 'normales' $y$ recurrentes, se apoya en una característica notoria del sentido común, su 'apariencia de obviedad y coherencia', su 'autoevidencia', que se refuerza por el hecho, constitutivo, de ser en buena medida compartido por las personas con las que usualmente se interactúa en una determinada comunidad; el círculo es inherente: el prejuicio socialmente instalado se autorefuerza a partir del peso de la evidencia derivada del hecho de 'todo el mundo sabe que....'

Los microprocesos de la reproducción social se hilan en las relaciones comunicativas posibilitadas por el pensamiento ordinario $y$ se fundan en la presunción de la validez de la realidad social tal como se da o presenta, así como de que esta interpretación es compartida por todos los demás, salvo unos cuantos 'raros'. En este marco, el lenguaje ordinario (la socialización lingüística), esencial para el estudio de la interacción social, pasa a ser un elemento fundamental de la integración normalizadora y justamente por eso se puede ver cuán limitado $y$ estereotipado se presenta, sobre todo en la 
cotidianeidad de los subordinados; no es solo un mecanismo de comunicación, es la comunicación del mecanismo alienante. Debiera estar demás el apuntar que evidentemente el sentido común se diferencia según la posición en la jerarquía social.

Entonces, en la vida cotidiana, a través de la reproducción de su vida inmediata, los individuos reproducen las condiciones de existencia de las instituciones de las sociedades en que viven y con un grado mínimo o nulo de consciencia sobre el resultado social amplio de su funcionamiento ${ }^{20}$. Esta rutinización, sentimiento de familiaridad, sensación de relativo control y previsibilidad, en contraste con un mundo social amplio, percibido (por los explotados/subordinados, incluyendo buena parte de la 'clase media asalariada') como exterior, extraño, incontrolable, altamente hostil, el mundo de las relaciones económicas y políticas, de las clasificaciones y compartimentos sociales y las diferencias culturales, permite entender que para buena parte de la población, la cotidianeidad sea vivida como un lugar de refugio, el espacio social del repliegue en lo privado (el yo interior, lo familiar, la vecindad).

Se trata, en las condiciones de una sociedad de clases (del capitalismo y de la explotación del trabajo humano), de una cotidianeidad saturada de elementos alienantes estructurales y estructurantes del modo de vida, masivamente reiterados por relatos 'normalizadores': "la vivencia de la cotidianeidad en tales sociedades es, ante todo, la de una vida alienada, una existencia que se contraría a sí misma..." (García, 2005, p.34). El mundo de la fetichización de las relaciones y la mistificación de las representaciones, mundo producido históricamente, pero vivido como deshistorizado, la desocialización/

$20 \quad$ Wright Mills plasmó con claridad en su artículo La promesa, el hecho de que la mayoría de los individuos viven sus vidas sin comprender el decisivo nexo con la sucesión histórica de la que hacen parte. Lo que saben y actúan está limitado por las órbitas privadas en que viven; en otros medios son espectadores y en la medida que consiguen alguna vaga conciencia sobre los acaeceres del mundo social amplio, se sienten atrapados. naturalización de lo social ${ }^{21}$. Pese a todo, un mundo experimentado por los explotados y oprimidos como uno que hace tolerable su vida; un mundo en el que pueden reconstituir algo de autoestima y obtener cierta consideración social; en el que incluso disponen de cierto margen para darse formas de convivencia no directamente dictadas por la jerarquía y con ello, momentos y lugares de disfrute compensatorio; en el que pueden también permitirse ciertas licencias respecto de la moral y la sexualidad castrantes; un mundo en el que paradójicamente se sienten no inferiores, sino iguales, de relaciones más horizontales, no verticales, como 'afuera' (donde se perciben y se sienten como extranjeros). La vida cotidiana como refugio.

Desde el punto de vista de la reproducción social amplia, de la 'historicidad', la cotidianeidad alienada, el mundo de la pseudoconcreción, constituye un dispositivo decisivo, en la medida que contribuye a la despolitización, atomización o fragmentación de los subordinados, a la reducción de su capacidad de resistencia, desarmando y promoviendo la resignación y la conformidad social ${ }^{22}$. Esta es la razón de que el objetivo civilizatorio de la emancipación social/libertad-realización personal, imponga como necesidad y pase por el trastorno y transformación en profundidad del mundo de la vida diaria y el sentido común modelados por el orden burgués (en una sociedad de clases, la socialidad, en sus rasgos definitorios, es conformada fundamentalmente por las relaciones de dominación, en el marco de la conflictividad social). Pero también explica, esta es una precisión decisiva, que los resortes fundamentales de la superación de la cotidianeidad alienada se encuentren más allá de ella misma. El locus central del proceso de desalienación es exterior y tiene que serlo, al

21 Trotsky, en Problemas de la vida cotidiana, muestra una notable comprensión del tema, estudiándolo para las condiciones, extremadamente difíciles, de los primeros años de la revolución rusa.

22 Esto explica la estrecha relación del pensamiento de derecha con la defensa de los hábitos de vida tradicionales. La vida diaria es recalcitrante, la 'toma de conciencia' choca con la tradición (Trotsky). 
mundo de la vida diaria, lo cual en realidad no es sino la formulación de una tautología, tal limitación está inscrita en la definición de la cotidianeidad.

Las condiciones sociohistóricas sobredeterminan o determinan estructuralmente las prácticas de los individuos a través de la modelación y ajuste de los términos de la vida cotidiana; 'las estructuras sociales deben ser interiorizadas por los individuos para que ambos puedan funcionar' (García, 2005, p.25). Si bien, estas condiciones sociohistóricas son creadas, construidas en la praxis social; praxis $y$ vida cotidiana no son sinónimos. Praxis es la clave de la actividad ontocreadora, de la historicidad (como autoproducción humana); la cotidianeidad es el ámbito de la reproducción de la vida de los individuos. Es decir, la praxis social engloba lo relacionado con la vida cotidiana, pero es mucho más. La reproducción del marco social más amplio, de la historicidad, pasa por la vida cotidiana, pero se realiza sobre todo, en la sociedad de clases, en la producción y reproducción de la vida material, en las luchas políticas y sociales, en el funcionamiento de las instituciones, en la dialéctica de integración y rupturas culturales, todos estos aspectos desbordan el medio de la vida cotidiana ${ }^{23}$. Por supuesto, el ámbito de la praxis transformadora, no solo desborda, se contrapone y socava los términos naturalizados de la vida cotidiana y su pensamiento ordinario. Tomada en sus límites,

$23 \quad$ No confundir vida cotidiana con "lo cotidiano de las diversas actividades y relaciones en que se involucran los individuos en las diversas facetas de su vida. La rutina de un laboratorio científico, la "normalidad' de la convivencia en un campo de batalla, o la familiaridad en un convento o en la militancia política, son formas de actividad altamente institucionalizadas, normadas y reguladas, por definición situadas en el más allá de la vida cotidiana. Los sentimientos y percepciones de los individuos acerca de su inserción en el mundo laboral son parte de su vida cotidiana, no su participación objetiva en la actividad productiva como tal, aunque esta última sea parte del fundamento concreto de la primera. no hay vida cotidiana 'revolucionaria'24, hay, o puede haber sí, vida cotidiana revolucionada ${ }^{25}$.

La vida cotidiana es rutinaria en tanto estamos sumidos en la "actitud natural" (Husserl, 1979); cuanto mayor nuestra comprensión crítica de lo social, mayor nuestra capacidad para intervenir activamente en la determinación consciente del carácter y rumbo del modo de vida, en todos los niveles de la relacionalidad (multiplicando nuestras opciones y rompiendo con prácticas autolimitantes). La desalienación de la vida cotidiana pasa entonces por una praxis de ruptura, transformadora de las pautas sociales y los códigos culturales de la dominación/opresión, informada y guiada por un pensar crítico, la racionalidad dialéctica. A partir de ahí, la clave para avanzar en la crítica de la cotidianeidad alienada, aspecto decisivo del proyecto emancipador, es la comprensión de la tendencia del poder social, bajo las condiciones de la sociedad de clases, a avanzar sobre lo privado, buscando sujetar la intimidad, colonizar

24 Entre otras razones porque no se dan en la vida cotidiana las condiciones para romper con la conciencia empírica alienada y alcanzar el 'para sî́, el transcrecimiento de la consciencia se da en la experiencia de la lucha de clases, en la organización y activación social.

25 El subjetivismo de las corrientes fenomenológicas coloca en el centro del análisis de lo social una noción de mundo de la vida entendida como lo vivido/experimentado, en una 'actitud natural' - los objetos y sucesos del mundo social, pero tal como aparecen para la conciencia empírica, el pensamiento de sentido común, no crítico-reflexivo-, perdiendo la dialéctica de lo subjetivo y lo objetivo en el seno de la totalidad social en devenir. La vida cotidiana se desborda hipertrofiada y la intencionalidad, pese a las protestas, termina por desmarcarse del contexto y las circunstancias. Un punto de partida subjetivista lleva a un punto de llegada hipersubjetivista. Los supuestos del enfoque y el modo de abordar el tema llevan usualmente a inconsistencias argumentativas. Por un lado, no pueden dejar de desconocer que el mundo de la vida es un 'legado de nuestros antepasados', que 'solo puede brotar de un yo y una consciencia que está siempre en constante interrelación con otros yo' (la intersubjetividad porta implícitamente, pero aún no explicita, lo histórico-social). Por otro, una $y$ otra vez derrapan hacia una concepción incondicionada de la acción dotada de sentido. 
de la subjetividad. La desalienación de la vida cotidiana, como dimensión de un verdadero proyecto emancipador, tiene que pasar por la crítica radical y la ruptura con los fundamentos mismos del orden social de la explotación/ dominación, matriz sociohistórica de la cotidianeidad. Por esto, la variopinta sucesión de estéticas 'transgresoras' y 'alternativos' estilos de vida, como tales, no van más allá de síntomas del malestar. Tan coloridos como inocuos.

Desde el punto de vista del marxismo, la Sociología es una disciplina decisiva, entre todo el conocimiento científico, porque es el ámbito de estudios que permite comprender las fuerzas sociales que modelan la sociedad, los marcos estructurales/institucionales en que se desarrollan los comportamientos en la intersubjetividad y el clima cultural (sistema significante) en que los individuos elaboran sus experiencias vitales, conocimiento que es una condición de posibilidad para una praxis transformadora y la superación de la sociedad de clases.

En un texto referencial, Wright Mills explicitaba lo que consideraba 'la promesa' de la Sociología: la 'imaginación sociológica', como forma de pensar, suponía el esfuerzo de conectar conscientemente los eventos de la vida personal con los problemas de la vida social; 'la forma más fértil de la conciencia de sí mismo'.

La Sociología es la ciencia paradójica, engendrada por las condiciones y necesidades resultantes del triunfo de la burguesía y su nuevo orden social. A comienzos del siglo XIX, su desarrollo se ve siempre pautado por dos tendencias en lucha: aquella que el marxismo enérgicamente contribuye a forjar, la que se representa como una teoría crítica de la totalidad social, constituyéndose así en la forma científico-social contemporánea de realización del proyecto intelectual de Hegel, la Sociología como instrumento privilegiado del autodesarrollo del espíritu, de la autoconciencia, del hacer consciente de la historia y de la construcción social, $y$ a la que este trabajo ha tenido la intención de contribuir.

Pero en su corriente principal, institucionalmente hegemónica, la disciplina tiende a ser realizada como 'ingeniería o administración social' (también puede ser divertimento postmoderno, en diversos registros). Intentando ignorar los conflictos estructurales y el carácter desgarrado de la vida social bajo el capitalismo, la autolimitación del individualismo metodológico, las pretensiones de asepsia axiológica (que, al romper la dialéctica de ciencia y valores, apenas maquilla el objetivo de clausurar la vía crítica), el olvido de la modelación de las circunstancias sociales y el clima cultural por el poder de la dominación, proponen una disciplina desdentada, que traiciona 'la promesa'. Intentan ignorar la realidad social, pero esta no los ignora a ellos. Un ámbito de estudios que se formula interrogantes sobre lo social, tarde o temprano tropieza con los tabúes que lo argamasan. Por eso en toda sociología, la más positivista o postmoderna, late un núcleo crítico, aunque sea no intencional. Por ello, la disciplina es siempre objeto de sospecha.

En general, si se piensa bien, no hay saber más importante que aquel que nos sirve para comprender $y$ hacer conscientemente, la sociedad que construimos y en que vivimos. La Sociología lleva a ver más allá de lo que aparece $y$ a transformar en extraño lo 'familiar'. El marxismo puede darle una mayor penetración crítica que cualquier otra corriente de pensamiento. Porque el marxismo es eso, una formidable herramienta teórico-metodológica para el conocimiento crítico de lo real.

Este artículo formula algunas proposiciones básicas para estudiar ciertos aspectos relevantes de la relación entre marxismo y Sociología. El objetivo ha sido avanzar sobre la forma de abordar la actualización del problema.

\section{BIBLIOGRAFÍA}

\section{LIBROS}

Adorno, T. y Horkheimer, M. (1971). La sociedad. Buenos Aires, Argentina: Proteo.

Anderson, P. (1987). Consideraciones sobre el marxismo occidental. México: Siglo xxı.

Ayala, F. y Cela, C. (2013). Evolución humana. Madrid, España: Alianza.

Bauman, Z. (2009). Pensando sociológicamente. Buenos Aires, Argentina: Nueva Visión. 
Berger, P. y Luckmann, T. (1968). La construcción social de la realidad. Buenos Aires, Argentina: Amorrortu.

Borón, A., Callinicos, A., Gruner, E., Bensaid, D. et ál. (2006). La teoría marxista hoy. Buenos Aires, Argentina: CLACSO.

Bourdieu, P. et al. (1985). El oficio del sociólogo. México: Siglo XXI.

Bourdieu, P. (1995). Por una Antropología reflexiva. México: Grijalbo.

Elias, N. (1990). Compromiso y distanciamiento. Barcelona, España: Península.

Engels, F. et ál. (1973). El materialismo histórico según los grandes marxistas. México: Roca.

Engels, F. (1974). Escritos. Barcelona, España: Península.

Engels, F. y Marx, K. (1971). Epistolario. México: Grijalbo.

Engels, F. y Marx, K. (1978) La sagrada familia. Madrid, España: Akal.

Fougeyrollas, P. (1992). Ciencias Sociales y marxismo. México: FCE.

Gadamer, H. (2003). El problema de la consciencia histórica. Madrid, España: Tecnos.

García, G. (2005). La producción de la vida diaria. San José, Costa Rica: Perro Azul.

Giddens, A. (1992). Sociología. Madrid, España: Alianza.

Giddens, A. (1998). Capitalismo y la moderna teoría social. Barcelona, España: Idea.

Giner, S. (2013). Historia del pensamiento social. Madrid, España: Ariel.

Goldmann, L. (1979). "Epistemología de la Sociología". En: Tratado de lógica y conocimiento científico. Buenos Aires, Argentina: Paidós.

Goldman, L. (1975). Marxismo y ciencias humanas. Buenos Aires, Argentina: Amorrortu.

Harris, M. (1995). Nuestra especie. Madrid, España: Alianza.

Heller, A. (1977). Sociología de la vida cotidiana. Barcelona, España: Península.

Hegel, G. (2000). Enciclopedia de las ciencias filosóficas en compendio. Madrid, España: Alianza.
Horkheimer, M. (1977). Teoría Tradicional y Teoría Crítica. Buenos Aire, Argentina: Amorrortu.

Horkheimer, M. (1982). Sociedad en transición: estudios de Filosofía Social. Barcelona, España: Península.

Husserl, Edmund. (1986). Ideas relativas a una fenomenologia pura y a una filosofia fenomenológica. México: Editorial Fce.

Kalivoda, R. (1971). Marx y Freud. Barcelona, España: Anagrama.

Kofler, L. (1968). La ciencia de la sociedad. Madrid, España: Rev. de Occidente.

Kosik, K. (1987). Dialéctica de lo concreto. México: Grijalbo.

Lamo de Espinosa, E. et ál. (1994). La Sociología del conocimiento y de la ciencia. Madrid, España: Alianza.

Lefebvre, H. (1972). La vida cotidiana en el mundo moderno. Madrid, España: Alianza.

Lenin, V. (1987). "Cuadernos Filosóficos". En Obras completas. Madrid, España: Akal.

Lowy, M. et al. (1982). Sobre el método marxista. México: Grijalbo.

Marcuse, H. (1978). Cultura y sociedad. Buenos Aires, Argentina: Sur.

Martín-Baró, I. (1992). Acción e ideología. San Salvador: UCA.

Marx, K. (1979). Contribución a la critica de la Economía Política. Madrid: Ed. Alberto Corazón.

Marx, K. (1980). Manuscritos económicofilosóficos. Madrid: Ed. Alianza.

Marx, K. (1982). La ideología alemana. La Habana, Cuba: Pueblo y Educación.

Marx, K. (1978). "Prefacio" e "Introducción de 1857". En Contribución a la critica de la economía política. Madrid, España: A. Corazón.

Marx, K. (2003). El dieciocho brumario de Luis Bonaparte. Madrid: Ed. Fundación Federico Engels.

Marx, K. ; Engels, F. (1973). Manifiesto del partido comunista. En: Obras Escogidas. Moscú: Ed. Progreso.

Moreno, N. (1981). Lógica marxista y ciencias modernas. México: Ed. Xolotl. 
Novack, G. (1977). Para comprender la historia. Bogotá, Colombia: Pluma.

Piaget, J. (1972). Epistemología genética. Rio de Janeiro, Brasil: Ed. Vozes.

Piaget, J. (1979). Psicología y Epistemología. Barcelona: Ed. Ariel.

Piaget, J. et ál. (1979). Epistemología de las ciencias del hombre. Buenos Aires, Argentina: Paidós.

Piaget, J. (1980). El estructuralismo. Barcelona: Ed. Oikos-Tau.

Rozitchner, L. (1988). Freud y los limites del individualismo burgués. México: S. XXI.

Trotsky, L. (1988). Problemas de la vida cotidiana. México: Cuadernos de Pasado y Presente.

Trotsky, L., Novack, G. y Moreno, N. (1977). La ley del desarrollo desigual y combinado. Bogotá, Colombia: Pluma.
Weber, M. (1977). Economía y sociedad. México: Fondo de Cultura Económica (FCE).

Wolff, M. (1996). Sociologías de la vida cotidiana. Madrid, España: Cátedra.

Woods, A. y Grant, T. (2002). Razón y revolución. Filosofía Marxista y ciencia moderna. Madrid, España: Fundación F. Engels.

Wright, C. (1979). La imaginación sociológica. México: Fondo de Cultura Económica (FCE).

Zeitling, I. (1973). Ideología y teoría sociológica. Buenos Aires, Argentina: Amorrortu.

Fecha de ingreso: $29 / 10 / 2015$ Fecha de aprobación: 25/06/2016 